\title{
Education and COVID-19: Learning Arabic Language and Perspectives
}

\author{
Nassima Kerras ${ }^{1}$ and Moulay Lahssan Baya Essayahi ${ }^{2}$ \\ ${ }^{1}$ Universidad Pompeu Fabra, Spain \\ ${ }^{2}$ Universidad de Granada, Spain \\ nassima.kerras@upf.edu \\ baya@ugr.es
}

\begin{abstract}
The study discusses the online teaching and learning of Arabic in order to evaluate students' difficulties and the way in which to approach this language in an interactive way, overcoming the barriers of computer screens. Nevertheless, e-learning is the future of education and it is crucial to offer a quality education, implementing emotional learning consciousness within the academic community. The COVID-19 pandemic impacted practically every country in the world. It created an extremely difficult global situation, and humanity found itself faced with an emergency state of working online and swiftly adapting its routine to a new reality. This was certainly the case in Spain when, in mid-March 2020, students were forced to study from home and teachers to teach at a distance. COVID-19 - and its related restrictions arrived suddenly, and there was little to no time to acclimatise to the new way of studying. The objective of this study is to analyse the difficulties faced by students of Arabic as a foreign language, and to offer some recommendations to improve online teaching, applying the communicative framework, combined with the importance of introducing the psychology theories and emotional education which is key to obtaining positive results. First, the topic is introduced, then the way to teach and learn the Arabic language online is discussed. Afterwards, the methodology is defined, highlighting the relation between emotional education and the Communicative Approach. A hypothetical-deductive method is applied to this analysis. A questionnaire is responded to by students of the Arabic language in Spanish universities in order to get an insight into their difficulties when learning online. A qualitative study is carried out in order to analyse the problems faced by the students and offer some possible recommendations to improve the quality teaching of Arabic as a foreign language, based on the perceptions of the students, taking into account the social context experienced during the 2020-2021 academic year.
\end{abstract}

Keywords: Learning Arabic Language, COVID-19, Psycholinguistics, Dynamics of Language, Teaching Arabic, Emotional Communication

\section{Introduction}

When the COVID-19 virus was first identified in Wuhan, China, in December 2019, a feeling of concern reached all corners of the world, though, little did people realise just how huge an impact COVID-19 would have. It later became apparent that, in a large part due to the relative freedom of movement between countries, the virus would spread alarmingly quickly. Indeed, just a few short months later, many countries found themselves in the midst of an uncontrollable situation, as the unknown virus began to seriously threaten the lives of the citizens all around the world. Given the distinct lack of warning, scientists - though not for the want of trying - were unable to find a quick remedy, and societies were left ill-prepared to face this crisis.

The first official cases of covid-19 in Spain were confirmed in March 2020 and a matter of days later, the central government took the decision to impose a total lockdown (Cabrera, 2020, p. 115). This was a completely unknown situation for the majority of Europeans, and one which created a feeling of insecurity, stress and perplexity. University students were not exempt from this feeling as they were, from one day to the next, forced out of their lecture theatres and onto their computers to embark on their distance-learning journey. As explained by Priyo Atmojo and Nugroho (2020, p.50): "This pandemic causes the fully online language learning to occur in a sudden and completely unprepared situation".

Even under normal conditions, studying the Arabic language is an immense challenge for students at Spanish universities. When opting to study this language, the Spanish learners are fully aware from the outset that they are attempting to grasp a Semitic language - a language with a completely different alphabet and characters, vocabulary with different roots, and considerably more complicated grammatical structures than other Latin languages such as French and Italian. The already-daunting challenge of learning Arabic is intensified even further when adding the COVID-19 complications, and online learning, to the equation. Even though the classes are done by videoconference, thus offering the students the possibility to practice, ask and interact with the teacher and classmates live, the computer screen creates an additional, unwanted obstacle, as Octavio (2021, p. 45) states: with the arrival of the post-COVID era, it could be necessary to modify the archaic structures on 
which our current educational system is based. This situation has been discussed in detail by several specialists including Rapanta, et al. (2020, p.923) who commented: "The COVID-19 pandemic has raised significant challenges for the higher education community worldwide. A particular challenge has been the urgent and unexpected request for previously face-to-face university courses to be taught online".

Universities were presented with the task of, in a just few short days, adapting the necessary online platforms in order to offer classes respecting the usual schedule, only now they would be held in virtual classrooms (Cabrera, 2020). This online mode permits the continuity of teaching directly through screens, virtually and rather importantly - live. Each university in Spain opted for the fully virtual or online learning, although some other possibilities were proposed during the second wave of COVID-19. This is reported by Priyo Atmojo and Nugroho (2020, p.52): "The widespread use of online learning inevitably brings students into alternative places for online language learning (Plaisance, 2018). Online language learning (OLL) may point various learning adjustments, namely a web-facilitated learning, a hybrid or blended learning, and a fully virtual or online learning".

In Spain, the glaringly obvious factor that has changed is the shift from the traditional face-to-face classes to an online mode, but many further difficulties arose as it progressed (Area-Moreira, et al., 2021). A case in point is related to technological knowledge and equipment; some students experienced difficulties attending the online sessions due to Internet and Wi-Fi problems, while others encountered troubles with the platforms. However, it was only a minority who suffered from these problems. A much more common issue is in fact a mental one. Students find themselves in the near-impossible situation of trying to concentrate for hours on end in front of a screen; interest can easily be lost, especially given that classes can be taking place in large groups with infrequent involvement of the participants. Octavio considers that the lack of real and effective digital competence within the classroom became clearer when the traditional face-to-face class model was replaced with an "emergency" online teaching model (2021, p. 48).

This article offers an opportunity to reflect on the needs of students of Arabic as a foreign language. As it is a different and difficult language to learn, it is hugely important to accompany students in online teaching and it also gives educators the opportunity to introduce emotional mechanisms in order to offer an attractive learning environment, despite the difficulties encountered due to the nature of the language and the new way of teaching.

\subsection{Research Problem}

This study analyses the problems encountered by Arabic language students in Spain to investigate their needs and offer possible recommendations that could improve education in the linguistic field to achieve a quality education, which is one of the objectives of sustainable development. It is part of the role of the modern-day teacher to detect the problems encountered in class in order to offer solutions that allow education to be improved and promote emotional education, which is important for successful results and, above all, to train citizens to be capable of reflecting and adapting to the changes that arise in life. E-learning causes several difficulties: the discomfort of spending hours in front of the screen, little participation by some students, low levels of concentration and the lack of motivation to encourage reflection of the methodologies that could help to engage the student in the class (Teräs, et al. 2020, p. 863).

E-learning is not a passing fashion, but it is the future of teaching and it is time to prepare ourselves to produce a quality education for future generations. Several other factors that slow down the teacher's dynamic must also be considered, such as the reduced time of the classes, the increased need to translate into another language to achieve some goals due to the few hours per week of Arabic class and the way of evaluating the learners, as well as the necessity to include technology-based pedagogy (Al-Awawdech and Alshtaiwi, 2020, p. 11551).

The biggest questions posed in this research is: what are the problems encountered by students of the Arabic language? And what will be the best way to correct these failures and help improve the e-learning that is the future of teaching?

The following section analyses the factors that have hindered the teaching and learning of the Arabic language online. 


\section{Literature review}

\subsection{Learning Arabic language}

Arabic teaching has abruptly changed from the face-to-face mode to the online mode and several points should be taken into account in order to offer possible explanations regarding the difficulties encountered by the students.

Communication in language classes at university tends to be direct. The teacher is the sender of the information or the message and the students are recipients (vertical communication) and when it comes to language and culture classes both parties play an active role in the class (horizontal communication). However, being forced to partake in online classes typically has a negative influence on student motivation and interest, further complicating the environment in which the class takes place (Coman, et al., 2020). This point is explained by Priyo Atmojo and Nugroho (2020, p.78) as follows: "In online learning, it is also hard to strengthen the emotional bond between the teacher and the students. It is due to the absence of physical touch and interaction in online learning".

The screen as a channel for broadcasting information quite clearly hinders the enthusiasm of students and creates a barrier between the student and their teacher as well as between the student and their classmates, which is a factor that impedes fluid communication, and that requires a certain air of technological solutionism (Trujillo Sáez, Merino and Gabarrón Pérez 2019, p. 154). In order for communication to remain effective, this handicap must be overcome, and systems must be improved by specialists in the educational field. Reimers and Schleicher (2020, p.7) explain it like this: "Education leaders should adopt a proactive approach to contributing to the mitigation of the impact of the Pandemic and to prevent learning loss during the period of necessary social distancing".

Once communication has been lost with a single student, for whatever reason - and there are several causes, such as misunderstanding, poor signal or purely the difficulty of the topic discussed - communication can quickly be lost with the rest of the participants. Trying to re-establish the initial lost connection requires some time and can in turn lead to other members losing interest as their attention wanders to other, non-related topics and their attention can be diverted by distractions such as a mobile phone. Recapturing focus demands innovation through the implementation of different creative processes (Octavio, 2021). With this loss of concentration, the train of thought is lost, and regaining it requires a great effort. In this case, extrinsic motivation is required, which means that the students expect something to happen to motivate them (Van Nguyen and Haòk, 2021). If each student expects an external incentive to mentally reconnect and follow the flow of the class, the teacher is faced with different personalities with different characters and a variety of interests. Student expectations can also be varied, as explained by Rapanta, et al. (2020, p. 929): "Simplify; cut back expectations; help reduce anxiety. Students will simultaneously be having to adapt to new ways of teaching and learning and deal with all the logistical complications and emotional stress of the pandemic and its associated lockdown".

It seems that the responsibility returns to the student to improve their concentration skills and not allow their attention to be diverted by other distractions, but the teacher must also cater to each individual student's interests and teach the language in a dynamic way that makes it more personal and relatable for the learner in a fun and stimulating way. This is a far from straightforward task. In addition, attentively listening to classmates provides a huge benefit, as students are given the opportunity to take advantage of the mistakes of others and promote deductive learning. However, it is difficult for this learning method to be applied and controlled through screens (Pérez-López, Vásquez Atochero and Cambero Rivero, 2021), especially when students opt not to turn on their cameras, making it even more difficult for the teacher to perceive what has and has not been understood.

Fortunately, there are several useful platforms which allow for group work to be carried out. By dividing the class into several reduced, private groups, bonding and closeness between students is enabled, providing the option of speaking directly with their peers in order to debate, exchange ideas and complete exercises together. These are activities which generally stimulate students who do not want to speak in class from behind a screen (Amutan, et al. 2020). 
Not only does learning Arabic require a huge exertion during the timetabled lessons, but students must also make a conscious effort outside of the scheduled hours. Extra studying in the students' own time and reviewing to reinforce vocabulary learning, for example, and not just revising the day before an exam is more than recommended: it is essential. Further difficulties arise here. The material in Arabic must be clearly explained, enabling unsupervised studying. The material is often written only in Arabic and the student may well become discouraged should they have to translate everything into their native language. Therefore, effective communication through email is needed so that the student knows exactly what to do in their own time for selfstudy sessions.

Another issue arises here, which is that the teacher can be forced to translate the classes into other languages so that the students do not get left behind, especially given that time is even more restricted when teaching online (Vermes, 2010), although other scholars consider it a beneficial option for language teaching (Dagilienè, 2012, p.128). An ideal teaching methodology does not include translating into other languages, something which is feasible in face-to-face sessions given that the teacher can use various objects, methods, or non-verbal communication to help get the message through. Online classes, however, do not facilitate this communication and as a consequence translation is often used; a recurring problem especially with beginner levels, and even more so in Arabic. Without these translations, the student is faced with a language which is extremely difficult to understand and that can quickly lead to a loss of attention and interest; once the frustration sets in, it is difficult to keep up with the lesson right until the end (Coman, et al. 2020). For these reasons, the importance of looking for, and using, various communicative and interactive tools helps to capture and maintain the students' attention cannot be underestimated. Rapanta, et al. (2020, p. 925) explain: “Online learning and teaching involve making use of a diverse array of tools, resources, pedagogical approaches, roles, organizational arrangements and forms of interaction, monitoring and support-with many possible combinations of substitution and integration".

Therefore, both the teacher and the student must be flexible, open-minded and willing to learn these tools, as discussed: "In the COVID-19 emergency situation, teachers have, almost overnight, been asked to become both designers and tutors, using tools which few have fluently mastered" (Rapanta, et al., 2020, p. 926).

Faced with these challenges and a rapidly changing role, teachers have a far greater task.

\subsection{Teaching Arabic language}

The teachers have the great responsibility of transmitting information whilst at the same time arousing the interest of the student, thus all information must be well-presented, understandable and practical. Of course, the collaboration of the student is vital if the outcome is to be a positive one. University professors have had to adapt quickly and seamlessly to the online platforms and a brand-new set of technological systems (Maican and Cocorada, 2021). Ideally, Arabic teaching should adapt to this technology for effective communication in the classroom.

The teacher must make the effort to create extra material, especially audio and visual content, to allow the new concepts to be easily understood. Students born in the $21^{\text {st }}$ Century are used to having large amounts of information thrown at them and the easier and more accessible it is, the better it is for them. Hence, platforms such as PowerPoint - with descriptive images and videos with easy-to-absorb illustrations - are key to helping the student study alone at home. A variety of resources can help teachers, such as glossaries, word banks, sample or model responses, sentence starters and clear and concise instructions (TNTP, 2020).

Effective use of materials in online teaching is a key ingredient, as it is a constructive way to present content accurately. Suitable materials are accurate in content, accessible to students and adequate to their level of autonomy; moreover, they should fit within the overall learning design (Pokhrel and Chhetri, 2021, p.139). Some materials might have the desired effect because they are thought-provoking and stimulate reflection, others because they require interaction, others because they present the content clearly, etc. The same could be said for students producing material; it can be an intriguing and useful activity as long as it is strategically placed in the course syllabus. Distance learning offers numerous ways of efficiently transmitting information.

The most effective form is often said to be the synchronous mode so that direct contact with the student is constantly maintained, though features of the asynchronous mode are, on occasion, also recommended (Perveen, 2020). In Spanish universities, individual tutorials are often offered, and it is a benefit that the student 
can take advantage of to resolve any problems or misunderstandings that they might be reluctant to bring up in a full class with their peers. In addition, the creation of PDF documents and video compilations detailing the vocabulary studied in class are simple but effective ways of informing students and aiding their learning after the class, despite the communication being via email rather than direct.

Another issue to be addressed in this article is the assessment of students. One of the primary concerns is exams, with the length of the exams in front of a screen prompting complaints from a number of students. One methodology that many universities are following is to set time limits for each individual question. Some potential barriers can be overcome by creating pre-test practices so that students can train prior to the day of the exam. Repetition is one way of helping students improve this part (Ghazi-Saidi and Ansaldo, 2017) and some methods include creating online quizzes in the forms of multiple choice and true or false questions. Online written exams are said to be particularly frustrating for the majority of Arabic language students.

For students tackling their end of degree projects, communication can be sped up by using a wider variety of tools. As these projects are completed individually or in very small groups, it is possible to use the mobile telephone to facilitate communication, for instance holding question-and-answer sessions through the instant messaging application WhatsApp to give personal feedback.

It goes without saying that creativity is essential on the teacher's part, though the students must play their part by responding positively to the proposals (Cimermanova, 2015, p. 1971). Thorough preparation by the professor is highly important. However, the teacher's groundwork for an online class requires significantly more time, effort and inventiveness than face-to-face classes in order to give as much detail as possible to students, as clearly as possible, to suit a variety of contexts and learning styles.

The importance of student participation is obvious; hence, teachers must find creative, inventive ways to adapt the material, provoke dynamic exchanges, and challenge the student to participate and not lose their interest (Ellis, et al., 2019, p.1).

This brings us back to direct translation. This methodology is far from the most effective for achieving excellent results in language class because the student gets too used to, and possibly reliant upon, translation; it is a traditional method, but a method which makes it difficult to improve one's level of the Arabic language, as explained by Correa (2014, p.163): "The reality is that, after only six or seven semesters of language instruction, students are very limited in what they can do with language". Thus, the students' self-discipline to exclusively use the target language, in this case Arabic, is fundamental, despite the fact that online learning makes this difficult with the beginner levels.

In summary, the common goal is to achieve a high quality of teaching and this is attained through a great deal of effort from both sides: the teacher as the person responsible for transmitting the information and the student as the recipient of it. The teacher can provide socio-emotional support, innovation of education, discipline, incorporation of technology, individual tutoring and small learning groups to facilitate equal process in critical subjects which are fundamentally important (IESALC, 2020. p.6), and the student must collaborate - otherwise, the communication system fails. Interaction is essential in language classes (Deli Girik Allo, 2020), and pushing students to participate is more than recommended, as Guofang (2020, p.41) comments, promoting meaningful interaction in the classroom and engaging students in the assessment process are important. In this way, an equal and inclusive education can be provided for everybody (IESALC, 2020). The student must participate in this process to prepare or review the material that is written or orally communicated (Rapanta, et al., 2020, p.928).

Taking everything into consideration, the difference between face-to-face classes and online classes is limited to the following points: "[...] three key differences between face-to-face and online learning include (1) space and presence, (2) self-presentation, and (3) interaction" (Rapanta, et al., 2020). Therefore, online teaching and learning require careful consideration with regards to how technology can facilitate the types of interaction being sought.

\section{Methodological framework}

Various specialists studied theoretical approaches to language learning and acquisition, and contributed significantly to the study of language as a scientific discipline. Some of the noteworthy studies include: 
Bloomfield (Structuralism), Skinner (Behaviourism), Chomsky (Innatism) and Halliday (Socio-linguistic approach). These are extremely important theories of language learning (Assaiquli, 2013). In this analysis we focus on the contribution of the second linguist (Skinner, 1957) who advocates for the practice of the language in a favourable environment to be acquired. According to Assaiquli: "Thus, for the behaviourists, imitation and practice are the essential mechanisms for the language to be acquired or learned" $(2013$, p.38). Students in Spain do not live in an environment that favours the practice of the Arabic language, as there is very little contact with the target language; typically, the only reference they have is the teacher who listens for a limited period, which can vary depending on the amount of time offered by the university. This time should be used to maximise practice with phonetics, syntax and morphology; therefore, translating Arabic into a foreign language is not the best way to acquire the language (Dagilienè, 2012). The lack of exposure to the target language can be seen as a huge barrier for learners of Arabic. Students of the Arabic language do not have a great deal of opportunities to listen to and read in the target language in their day-to-day lives as can be done with other languages such as English, which is almost unavoidable; there is a huge amount of exposure to the English language due to its dominant presence in media, entertainment and commercial products in countries throughout the world. Arabic learners are limited to being exposed to Arabic in class if an extra effort is not made by the learners to search for additional resources. The pedagogical and virtual materials in Arabic are scarce compared to languages such as English and, to a lesser extent, Spanish and French.

The second reference mentioned in this section is Halliday (1975 cited in Assaiquli, 2013) who claims that language is learnt through understanding the cultural context. For the author, the meaning of words is built thanks to the understanding of the cultural context, and culture is interpreted in semiotic terms. It is a reality in which professors regularly find themselves when it comes to teaching Arabic as a foreign language. It is difficult to understand the denotation of words if the social context is not understood; hence, understanding the connection between the teaching of the language and the culture is essential for the proper functioning of the class. Some Spanish universities offer reasonable hours for teaching both areas, whereas others do not due to time constrictions. Here, too, time is a key to achieving goals, and online teaching - for now - is making it even more difficult to succeed, especially when the student becomes so easily distracted. For this reason, capturing the interest of the student is important and their cooperation is essential (Hlas, Neyers and Molitor, 2019).

Our position is aligned with Skinner and Halliday, which is that practice and repetition within the class allow for the understanding of phonetics and structures; and the teaching of the sociocultural context helps the learner grasp a foreign language. Kóvacs $(2017$, p. 84) agrees, highlighting the importance of teaching language and culture at the same time using various types of authentic materials.

The language must be taught from the point of view of phonology, morphology, syntax, sociolinguistics and pragmatics (Ellis, et al., 2019), without forgetting the psycholinguistic side because the importance of classroom phenomena is motivation; the relation between psychological variables and language learning, and the intersection between educational practice in general and language teaching in particular. The issue of psychology in language teaching is an interesting one, and even more so in teaching the Arabic language online during the lockdown period of 2020-2021. Psychology in teaching covers several topics and we focus on behavioural psychology (Cherry, 2016), which is an area of psychology, defined by Hanim Rahmat (2018, p.3) as: "a branch of psychology that focuses on the study and alteration of people's behaviours, including their actions, emotions and thoughts". Many studies were subsequently generated focusing on various points related to mind and language such as linguistic coding or decoding of it, the factors that affect linguistic perception, understanding, production of the language and emotional education (Guslyakova y Guslyakova, 2020).

Psychology is helpful in understanding the way of teaching and the way of language acquisition by students. For this reason, teachers look for strategies to convey the message so that it is understandable and enjoyable at the same time. Therefore, emotional communication is essential for the student to perceive the message more easily and with greater interest. It is important to propose activities that allow dialogue and participation to enjoy learning. In Online classes this is made possible thanks to the division of the class into small groups so that the students feel comfortable enough to converse and create dialogue. Taking into account the psychological side in language class is important as Aksoy (2016, p.65) points out: "Knowledge of psychological factors involved in the process of language learning and teaching is indispensable for teachers of languages".

Several theories are combined when teaching a foreign language, from the most classic, which is focused on the structure of the language and semiotics, to the more modern ideas which have a larger emphasis on the way of 
thinking of the student and the functioning of the brain. This study is not about analysing the set of theories, but combining them because each one contributes to high quality teaching. Skinner and Halliday's theories have been highlighted as they are fundamental for the teaching of any foreign language, and the theory of emotional education (Cohen, 2006, p. 27) is also emphasised as that allows us to understand the receiver of the information to optimise results.

According to Chou (2021) the psychology of education and positive emotions are important in improving the teaching-learning processes. Language is said to be closely connected to thought. This point is raised since the attitude of human beings towards any activity is conditioned by engagement and motivation and it is linked to the thought process. Hence, there is a need to study the elements that allow the acquisition of the language; the student's psychology is an essential component, as highlighted by Long, et al. (2011, p.6): “Pure' psychology tries to arrive at general theories that can help us understand basic areas such as learning, memory, motivation, etc. However, practical education is a complex situation and there are often many factors that interact or combine to give rise to a number of different effects".

A hypothetical-deductive method is applied to this analysis. It has been noted that students who have a tendency to study achieve good results regardless of the length of the class, while students who are less engaged in class, from the same group, complain about the difficulty of studying Arabic online and they find themselves losing concentration quickly. This hypothesis is defined as follows: "This process of identifying a theory, making a prediction that tests it, and then collecting data to see if the prediction is supported" (Long, et al., 2011, p.3). This statement is completely psychological because once the student has put up the barriers, keeping up with the class becomes more difficult, and without the student's motivation the teacher struggles to find a way to connect with them. The aim is to analyse this situation in order to propose some recommendations for the teaching of the Arabic as a foreign language.

A questionnaire is addressed to students in order to understand their motivations. A quantitative study measures the interest of students in studying the language online and assesses their concerns in order to obtain statistics that allow us to comprehend the principal concerns of the students.

Likewise, a qualitative study is carried out in order to describe the problems faced by the students and offer some possible solutions, based on the perceptions and emotions of the students regarding the new reality, taking into account the social context experienced in the year 2020-2021. As the authors (Long, et al., 2011, p.5) express: "The emotionalist model is primarily interested in looking at a situation from an individual's point of view, and is interested in perceptions and emotional reactions to situations".

The objective of the analysis is not merely based on a study of language skills (listening, speaking, reading and writing), but on understanding the student who is learning the Arabic language online during the pandemic. This pandemic has modified the routine of learners from the psycho-educational point of view, as the same authors claim: "When psychology is applied to a number of different areas in education, it has the potential to help us to understand what is happening, and to make more logical, informed decisions about the best way to organise the educational process" (2011, p.10).

Maslow (1962) considers self-confidence to be a need for survival alongside some other basic physiological needs. The author expresses the needs as follows: needs for self-realization (self-fulfilment); self-esteem needs (self-worth, success); social acceptance needs (affection, love); security needs (protection) and physiological needs (food, water, air). Fredrickson (2001) also presents positive emotions as ways to expand and develop their own skills. This is a requirement which is taken into account in the practical analysis.

A questionnaire completed by students is analysed in order to come to some conclusions about learning Arabic online and to prove the enormous importance of a motivation when learning a foreign language, such as Arabic.

\section{Data collection and analysis}

A questionnaire has been carried out through the Drive platform in order to find out the difficulties of the students. A total of 12 questions were asked and students were encouraged to answer with complete objectivity in order to gauge their true opinion. Some questions are open and offer an open space to answer, while others are closed questions and should be answered with a 'yes' or 'no' answer. 
These 12 questions address various aspects related to virtual teaching. The first three refer to questions related to the consequences derived from the change from face-to-face to virtual classes, the degree of influence of online teaching on student motivation and the relationship between the duration of the classes and the student's level of concentration. The next three questions focus on content such as the visual quality of the published and/or projected material, and the usefulness of current digital platforms for communication and their use for interaction between students. From questions seven to nine, the questionnaire addresses the student's preferences and whether they are more inclined to favour visual digital material or traditional textbook exercises, the difficulties that the student studying Arabic at home may encounter and the amount of effort, if any, the learner makes to complete the additional, optional exercises provided by the professors on the online platforms. In the last block of questions, the questionnaire covers aspects related to the student's organization to improve their learning and progress: if they choose to study and review weekly or only revise before an exam.

The questionnaire was published online on December 4th, 2020 and withdrawn on the 31st of the same month. It was mainly distributed among the students of some Spanish universities, although it was open to any Arabic language student wishing to participate. The results of each question are displayed as a percentage. 101 students answered and the results obtained are detailed in the next section.

\section{Results and discussion}

The results obtained show that $59.4 \%$ consider that the change from face-to-face classes to the online mode has been difficult for them for the following reasons: the difficulty of staying focused online, concentration issues, problems with contributing and participating in class and comprehension difficulties when attempting to interact orally, external distractions and the capacity to concentrate decreasing since there are more stimulus and it is harder to focus on a screen for 6 hours a day. Other concerns include: loneliness in front of the screen, the lack of taking notes because everything is done through the computer, lack of social interaction, being confined to the house for days and not having social contact having a deep effect on mental health, interaction restrictions, difficulty to be $100 \%$ focused on a lesson from the beginning to the end.

Some students reflect that in terms of grammar and writing it has not been so testing, though there have been more problems related to pronunciation and not being able to see exactly how the professor pronounces a word. The difficulty is also due to the fact that a totally different alphabet is used in Arabic compared to the Spanish language and other commonly-used languages in Spain, such as English and French. The lack of interaction with the professors and the other students means that greater levels of concentration are required online in comparison to attending a class in person, as well as some inevitable technical difficulties. These are commonlymentioned problems in literature reviews by various scholars (Pérez-López, Vásquez Atochero and Cambero Rivero, 2021). Some students have a more positive outlook and think that while it has been difficult in terms of taking notes, they have not noticed a huge difference and they are generally content with the results. Others believe that the more familiar with the online platforms and their functions they became, the easier the classes seemed. In addition, some students mention that the main problem was the general, unfortunate health situation created by the pandemic.
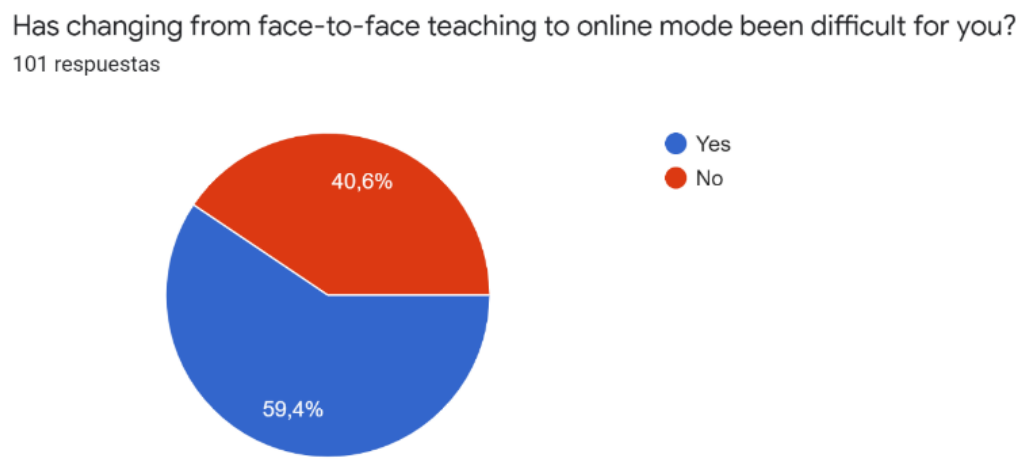

Figure 1: Changing from face-to-face teaching to online mode 
As shown in figure $2,64 \%$ of the students reported that their motivation did not decrease when learning the Arabic language in an online mode, compared to the traditional setting. Of the remaining respondents, some believe that paying attention is more trying; not physically seeing colleagues or being able to completely disconnect from the classes makes it even tougher. It has been argued by some students that language learning requires human interaction, and online classes lead to a considerable decrease in interaction and active participation, a point mentioned by Ollero Ramirez (2014) in her analysis. Others think that motivation has decreased in every subject, so it is not merely an issue of studying Arabic. The absence of the social aspect and studying together was the main factor for the decrease in motivation and the lack of concentration, as explained in the theoretical section. Therefore, emotional solutions to engage students is a necessity in pedagogy if educational quality is to be achieved.

\footnotetext{
Have online classes decreased your motivation to study the language?

100 respuestas
}

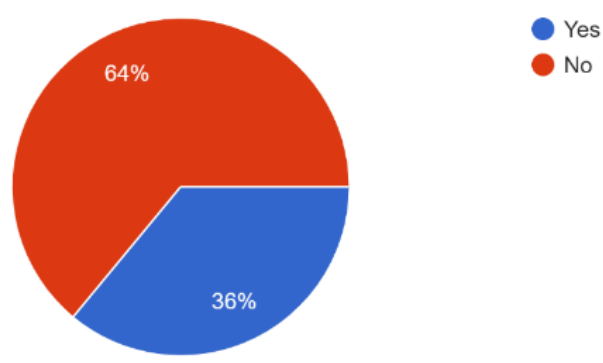

Figure 2: Motivation

Findings showed a substantial increase $(67.3 \%)$ in the number of students who consider that it is difficult to concentrate. The main struggles, according to the interviewees, are the following: the sheer quantity of classes to attend online, the distractions at home and a lack of concentration in a family environment, and a general mental fatigue caused by the monotony of being in front of a computer screen all the day; an aspect observed in the theoretical part. Laremenko (2017) highlights the importance of introducing online games to motivate language learners.

\section{Do you find concentration to be a problem due to the long duration of the class in front of a screen? \\ 101 respuestas}
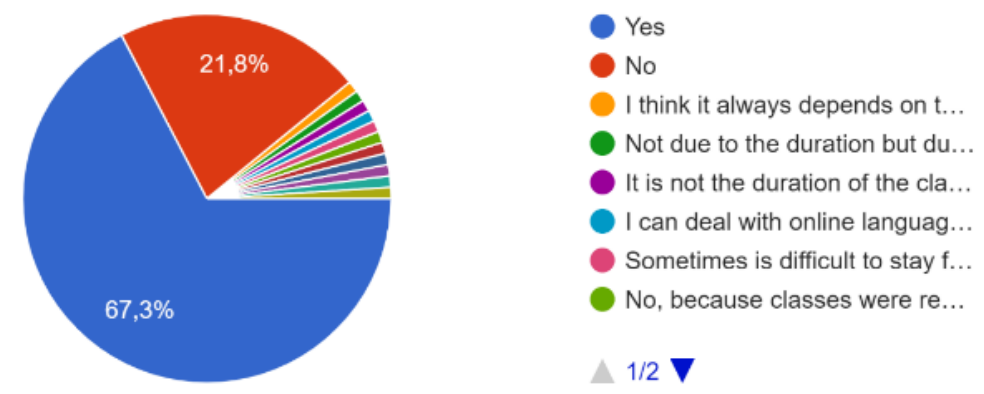

\section{Figure 3: Concentration}

Of the respondents, $88 \%$ indicate that the material posted, such as PowerPoint presentations, could be easily and clearly seen. Some suggest that videos are easier on the eye, while there are those who prefer the material physically, i.e., on paper. Thus, spending time creating audio-visual material is key to improving this aspect, even if this means that teachers having to dedicate a substantially greater amount of time and effort to their class preparation. 
Can the material posted, such as Power Point presentations, be easily and clearly seen?

100 respuestas
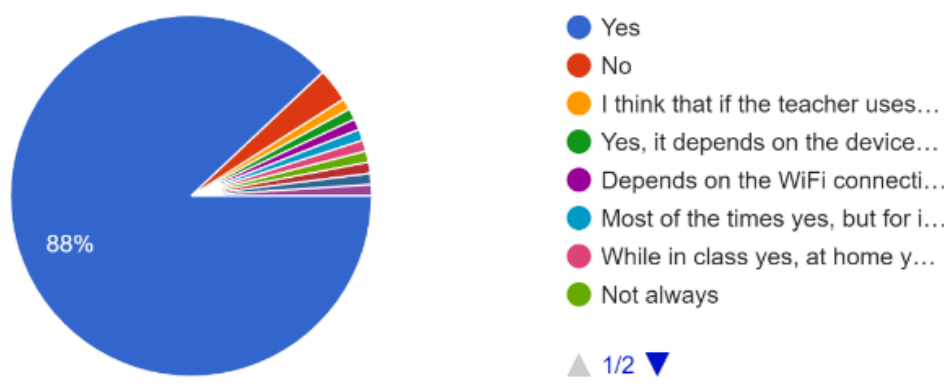

Figure 4: Material

$56.4 \%$ of the students think that the online platforms are practical for engaging in conversations with colleagues and helping to improve communication. It is an essential element that must be taken into account when striving to improve the methods and dynamics in the Arabic-language classroom. This is a point which is analysed in the theoretical segment and reflected throughout the survey.
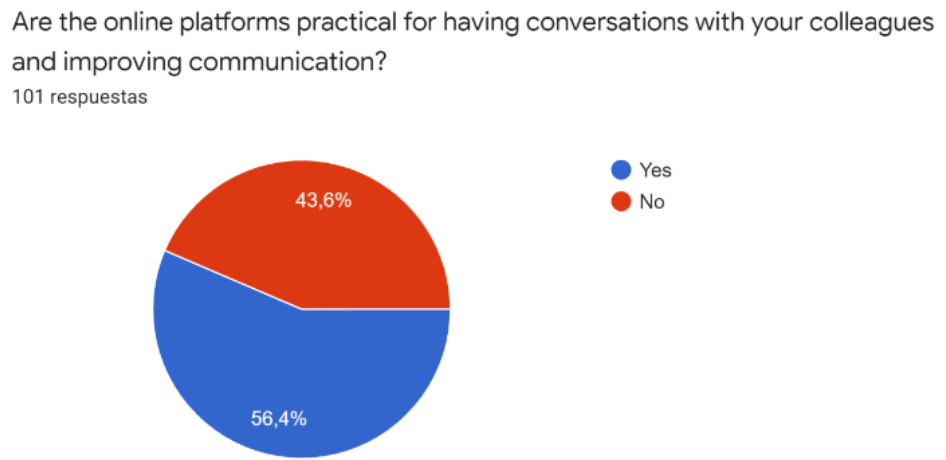

Figure 5: Communication

$65.3 \%$ of the students consider it possible to maintain interaction with colleagues through the platforms. Educational emotion is crucial in improving and maximising interaction between students, and it can be achieved with the help of creativity and coordination between teachers. Emotional education is key to boosting the ability to solve problems flexibly and responsibly (Gallardo-López, 2018, p. 2).

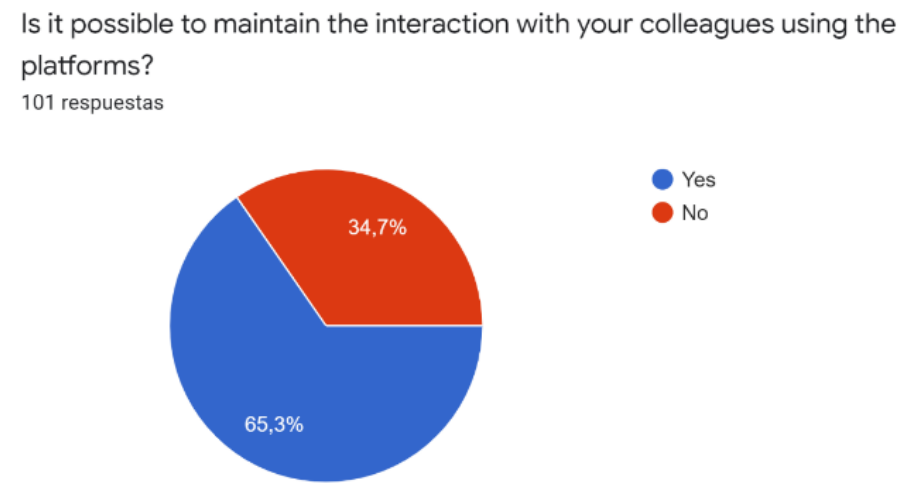

Figure 6 Interaction 
$60 \%$ of the respondents consider that the visual material (such as Power Points and videos) is more interesting for them than the exercises in the book, while the rest do not agree. Some students consider that videos with Arabic and Spanish subtitles and simple images that help memorize new words or expressions are welcome because it makes the class engaging, interesting and more easily understood. Others prefer a combination of the textbook and extra material. Visual material, in general, is helpful according to the students and some consider that short quizzes, such as Kahoot, are useful. As discussed in the previous section, time-consuming though it may be, it is a worthwhile effort to offer aesthetically pleasing and stimulating material which helps keep the all participants engaged for the duration of the lesson, as we have analysed it in the theoretical approach
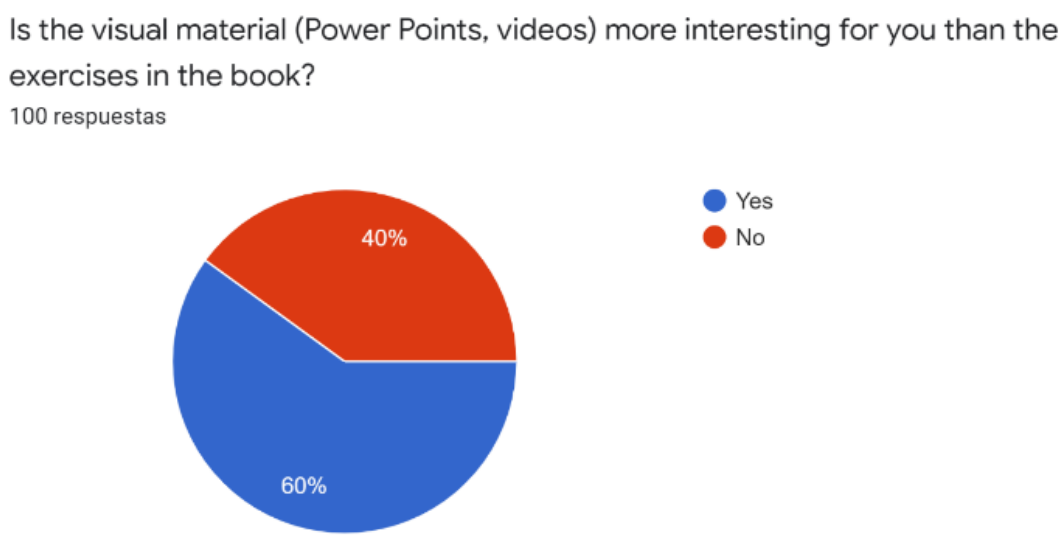

Figure 7: Visual Material

Only $32.7 \%$ of the students think that it is difficult to study at home due to the material being written in Arabic and there being difficultly in understanding the words and sentences. For some students, learning the content is less attainable because they are alone and sometimes there is no one to ask regarding specific issues; others claim that it's not so hard because there is access to online dictionaries. For some students, understanding the material is difficult even when attending class in person. Some students think that it was quite challenging to learn the basics of Arabic, but progressing from the basics is not so hard. In addition, teachers can always be asked to clarify any difficulties by email. For others, the videos are usually more difficult to fully understand. Once again, the need to accompany the students to provide quality teaching is plain to see, as we have seen in the literature review.

\section{Is it difficult to study at home because the material is written in Arabic and it is difficult to understand the words and sentences? 101 respuestas}
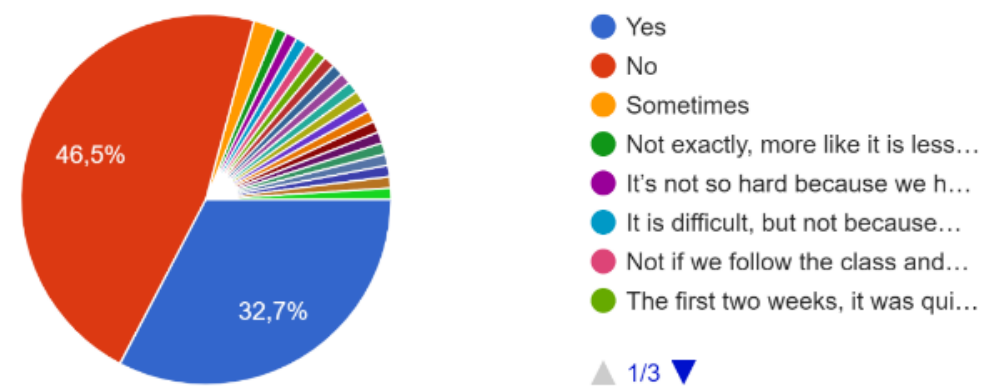

Figure 8: Arabic Material

A total of $70.3 \%$ of the students affirm that they take the time to study independently by listening to audios and/or reading vocabulary lists posted on the online university platform. Some students claim that they do not 
have enough time to do so and they intend to find some time during the University holidays to recap everything and begin memorizing the vocabulary. Others do it sometimes but not always, since it is difficult for them to find the self-motivation without attending weekly classes in person. It is, once again, clearly shown that the support of teachers is more than necessary and motivation is key (Darling Hammond, et al., 2019) to help learners overcome these difficult times and continue their development and education.
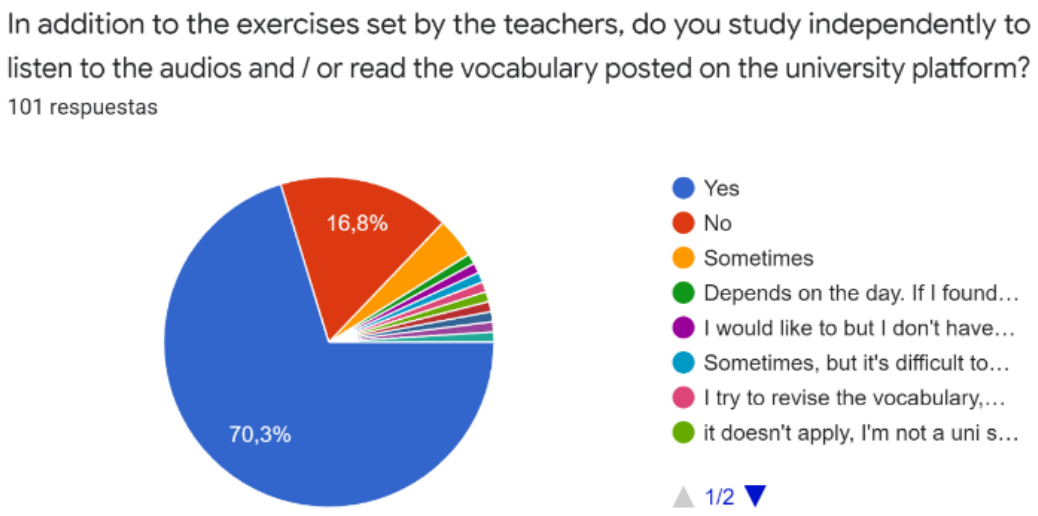

Figure 9: Study independently

When asked how many hours they spend at home reviewing and revising the lessons, the majority of students said that they study for one hour a week, a reasonable percentage between two and three hours a week, while a minority dedicate four hours a week to review and revision. Some students study just before the exams because they have other subjects, apart from Arabic, to dedicate their time to and it is nigh on impossible to fully commit to everything when having online classes. $57.4 \%$ of the respondents state that they review the content of the classes weekly, while and $42.6 \%$ admit that they do not do so.

This question is not concerned with students preparing the content before the classes, but reviewing and consolidating material from previous classes. Some linguists do, however, choose to push students to prepare the content before the class. It has been suggested by Algayres and Triantafyllou (2020, p.397): "The Flipped Classroom (FC) is an instrument method, where the traditional lecture and homework sessions are inverted. Online material is given to students in order to gain necessary knowledge before the class, while call time is devoted to application of this knowledge and reflection".

There are, however, counter arguments to this idea, since students regularly require substantial support, professional guidance and reassurances from the professors. It has also been shown that the educators must carefully assign appropriate tasks which will aid the students' development, arouse their interests and, fundamentally, not discourage them from studying Arabic.
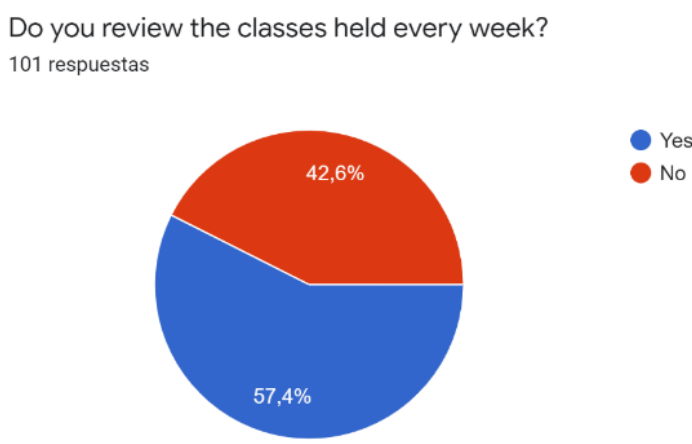

Figure 10: Review Classes 
The following chart shows that $56 \%$ of the respondents study the language just before the exams. Some review a little during the year, but leave most of it until just before the exam. This further reinforces the viewpoint that the students require external support and motivation in order to be consistent with their work, and that they approach their studies with a positive attitude, as well as being engaged enough to fulfil their potential (Yengin, et al., 2010).

\section{Do you review the classes held just before the exam? \\ 100 respuestas}
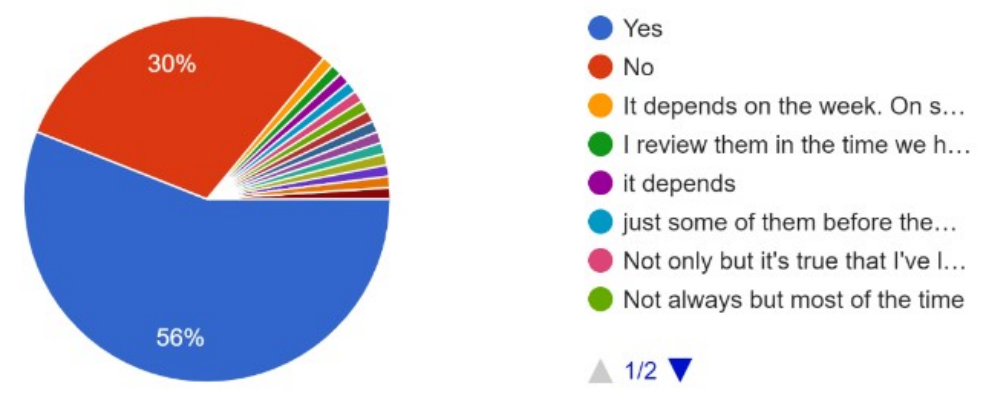

Figure 11: Exams

Some observations and recommendations with regard to the learning Arabic Online are exposed in the following section. The results obtained through these surveys shows a variability in the responses. Some $59.4 \%$ of the students consider that the new learning methods thrust upon them due to the COVID-19 pandemic have been difficult for various reasons. We highlight the issue of being in front of a screen for several hours at a time, the vulnerability to distractions at home, the lack of social interaction which negatively impacts the mood of the students, and some technological malfunctions. A high percentage consider that they have adapted to the new modality and that the situation is gradually becoming easier for them. Motivation to study the language has not decreased substantially, although a number of students consider that socialising and human interaction are essential to effective studying of the language. Concentration is another handicap to which the student is exposed when studying the Arabic language online and it is suggested that this is largely due to the amount of time per day spent in front of the computer that creates general fatigue, though this is not specifically or exclusively when studying the Arabic language. Audio-visual material is welcomed by most students, although paper material is equally valued; a combination of both - audio-visual and paper-based material - seems to be the most effective method. In addition to the traditional means of teaching, students appreciate the introduction of online games. More than half of the students consider that the platforms allow interaction between the teacher and their classmates, although some do not fully agree and consider that it is difficult for them to participate in discussions during online classes. The majority of the respondents (88\%) agree that the material displayed on the platforms can be easily understood, even when presented in Arabic, because it is usually explained in advance and the teachers can always be contacted by email to ask or even use an electronic dictionary, while $12 \%$ consider the platform complicated to use and fully comprehend. Most of the students confirm that they consult the material posted on the university platform or sent by mail. The regularity in reviewing at home is variable, but a majority study the Arabic language for an hour a week, others less than 60 minutes and a decent percentage more than an hour. According to the answers, some students seem to be constant and others less so regarding self-study during the semesters.

These results lead us to believe that university students are still at an age and a stage in their development which calls for the help of teachers in order to tackle these problems competently. The responsibility of teachers to create a communicative environment in Arabic language class is essential, as well as the need to promote an emotional approach. This is all viable thanks to the teacher's emotional intelligence that promotes effective learning and academic performance (Guslyakova and Guslyakova, 2020, p. 782). In this way, the emotionality of the students is understood, and an attempt is made to create a connection that allows for the establishment of a pleasant learning environment with a little creativity and, therefore, the student is much less likely to disconnect from the class despite the potential fatigue caused by the overwhelming use of technology. 
For this reason, it is imperative to encourage students in order to get their attention, as explained (Cui and Coleman, 2020, p.552): "Thus, the flipped classroom approach might improve student motivation, both intrinsic and extrinsic, as it creates such scenarios for students. And if the students are more motivated, they might be willing to complete a significant amount of learning activities both inside and outside the classroom".

The general results of Arabic language students have not changed since switching to the online mode, in respect to their level of learning in face-to-face mode, and satisfactory results are usually reached; this year has not been an exception despite being surrounded by a feeling of insecurity in the face of Covid-19. Everything can be improved using a lot of creativity and stimulating pedagogy in a dynamic way, encouraging self-awareness and self-organization with psycholinguistic strategies.

\section{Conclusions}

In this study some problems encountered by students when studying the Arabic language online during the COVID-19 pandemic have been considered and analysed. General considerations have been presented, accompanied by a questionnaire which has been completed by students in order to get an insight into their online education and to obtain a clear idea of their opinion. Finally, the emotional aspects that must be taken into account for the organization and preparation of classes have been considered.

The overall goal is to improve the whole learning experience for students, and adapt and develop the design and structure of the courses, integrating psychological and pedagogical knowledge and self-awareness. This makes the student aware of the need to maintain a regular rhythm, as well as help them find strategies to succeed in language learning. Dynamic activities in class are highly valued as well as being a way of helping to keep all students focused and interested, introducing more games in class and interactive materials, despite material in Arabic being scarce. It is time for each teacher to adapt their content individually or in collaboration with their colleagues to overcome this lack of ready-made material. It is essential to play with creativity and generate communicative situations of all kinds so that the student can practice the language with their classmates in small groups, introducing cultural information with relevant topics to reflect on, favouring current affair issues in order to avoid too much repetition of content. Dividing the groups to make the activity more dynamic and personalised gives each learner a greater chance to practice, though the amount of time granted by each university must be taken into account when preparing these activities.

This strategy implements positive aspects of psychology to help students to gain self-confidence; they will be able to contribute more and create a positive feeling towards their learning, while avoiding unnecessary stress and panic which can be provoked when studying a difficult language. It is imperative to assist the students, supporting their efforts to be able to do more, to transmit positive feelings and pushing them to continue in difficult times, such as the global one experienced in the year 2020-2021. And so, it is absolutely necessary to continue improving the quality of online teaching of the Arabic language as a foreign language, and also to open students' minds so that they have a solid insight into the functioning of Arab countries from the sociological point of view. This is a key element that allows one to reflect on this globalized world; a world which at the same time lacks sufficient information from other civilizations. Not only is studying languages a task of memorising phonetics and grammar, but it is also related to understanding culture and awakening an emotional education, interest and transversal competence. Arabic language teachers could push towards reflection and bring students closer to foreign cultural environments that could be more understandable, and thereby produce more tolerant societies.

These psychological aspects help the students to acquire, retain and process the information easily; and above all, motivate them, which is key to encouraging participation, allowing the communication to be bilateral and effective. Motivation influences the proficiency of the language and it is important to change the conventional methodology to a dynamic one as much as possible to develop socio-emotional competence in language class.

The communicative approach, the social character of the language, creativity and empathy in class are crucial when transmitting a foreign language such as Arabic. Empathy can be transmitted to students by explaining and understanding the difficulties that each student may have, and not all members of a class will be able to assimilate the information in a homogeneous way. Some students excel in oral communication, whereas others are far more comfortable communicating in a written way. It is not necessary to develop all the skills at the same pace, though explaining and correcting mistakes is vital. The demands of the communicative approach cannot 
be met if the student does not feel confident speaking; interaction with the classmates breaks down immediately. One thing that must be taken into account is the personality of each student and their potential obstructive barriers when speaking in public, as they vary from person to person and cannot be applied to all students equally. The teacher must be a competent observer to give appropriate feedback and advice to each student, and a positive reaction from the student is essential for effective communication and offering an integrating model and increase concentration and creativity.

It is obvious that the combination of the approaches mentioned in this work is stimulating, especially taking into account the current circumstances regarding the COVID-19 pandemic. Developing conventional skills (speaking, writing, listening) is a basic requirement that is generally acquired when increasingly innovative and interactive methods are sought. However, the communicative approach is essential for the student to practice the language in an appropriate context, taking into account the culture of the language taught. The psychological requirement, that helps create a pleasant environment for the student to relax and interact in class, can also not be forgotten; this psycholinguistic side is essential to consider, especially in Arabic class, due to the difficulty of the target language. As long as an adequate amount of class time is assigned by the universities, and the students cooperate, sufficient progress in the learning of the Arabic language can be made regardless of whether classes are carried out in person or online.

Following a communicative method for the student to master the Arabic language is an effective method in the language class, but developing emotional skills in education would allow the student to become even more involved in the learning process. In this way, it is possible that the interaction takes place in a pleasant environment, even if it is incredibly time-consuming for teachers to produce and prepare appropriate material and find the necessary emotional strategies. The results are rewarding for students, with the feeling of satisfaction that they are capable of communicating in a foreign language, as well as having a deeper understanding of cultural characteristics which had most likely been alien to them prior to the course. And that is a contribution to train responsible and committed individuals towards the global village in which they live, and transversal skills and effective communication are promoted in any language, not only in Arabic.

The research remains open to more proposals and methods that allow for the improvement of transversal skills for fluid communication between civilizations, and that drives interest in learning other languages that can be motivating in such a global society. In this way, it offers quality teaching and promising prospects for future generations. In this modest work, the problems related to learning the Arabic language through screens have been analysed, but there is still a long way to go to explore in order to offer pedagogical proposals for quality education.

\section{References}

Aksoy, K., 2016. Review of exploring psychology in language learning and teaching. Eurasian Journal of Applied Linguistics (EJAL), 2 (1), pp. 65-70.

Algayres, M. and Triantafyllou, E. 2020. Learning analytics in flipped classrooms: a scoping review. The Electronic Journal of e-Learning, 18 (5), pp. 397-409. DOI: https://doi.org/10.34190/JEL.18.5.003.

Amutan, K. I., Maruthai, E., Ching, H. S., and Ling, W. W., 2020. Challenges of learning English in $21^{\text {st }}$ century online vs. traditional during COVID-19. Malaysian Journal of Social Sciences and Humanities, 5(9), pp. 1-15. DOI: 10.47405/mjssh.v5i9.494.

Al Awawdech, N., and Alshtaiwi, M., 2020. Foreign languages e-learning: challenges, obstacles and behaviours during COVID-19 pandemic in Jordan. PJAEE, 18(6), pp. 11536-11554.

Area-Moreira, M., Bethencourt Aguilar, A., Martín-Gómez, S. and San Nicols-Santos, B., 2021. Análisis de las políticas de enseñanza universitaria en España en tiempo de COVID-19. La presencialidad adaptada. Revista de Educación a Distancia, 21 (65), pp. 2-19. DOI: https://doi.org/10.6018/red.450461.

Assaiquli, A., 2013. Theories of language learning: a contrasting view. Scholarly Journal of Scientific Research and Essay, 2 (3), pp. 34-43.

Bloomfield, L., 1933. Language. London: Compton Printing.

Cabrera, L., 2020. Efectos del coronavirus en el sistema de enseñanza: aumenta la desigualdad de oportunidades educativas en España. Revista de Sociología de la Educación-RASE, 13 (2) Especial, COVID-19, pp. 114-139. DOI: http://dx.doi.org/10.7203/RASE.13.2.17125.

Cherry, K., 2016. History and key concepts of behavioural psychology. [online] available at: $<$ https://www.verywellmind.com/behavioral-psychology-4157183> [Accessed 11 June 2021]

Chou, M. H., 2021. The mediating role of achievement emotions in the relationship between instructional clarity, English proficiency, and reading strategies. Educational Psychology, 41(5), pp. 582-601. DOI: https://doi.org/10.1080/01443410.2021.1882660. 
Cimermanova, I., 2015. Creativity in EFL teacher training and its transfer to language teaching. Procedia Social and Behavioral Sciences, 197, pp. 1969-1975. DOI: 10.1016/j.sbspro.2015.07.562.

Cohen, C., 2006. Social, emotional, ethical, and academic education: creating a climate for learning, participation in democracy, and well-being. Harvard Educational Review, 76 (2), pp. 201-237. DOI: https://doi.org/10.17763/haer.76.2.j44854x1524644vn.

Coman, C., Tîru, L. G., Mesesan Schmitz, L., Stanciu, C. and Bularca, M. C., 2020. Online teaching and learning in higher education during the Coronavirus pandemic: student's perspective. Sustainability, 12, pp. 2-24. DOI: $10.3390 /$ su122410367.

Correa, M., 2014. Teaching (theoretical) linguistics in the second language classroom: beyond language improvement. Porta Linguarum, 22, pp. 161-171.

Cui, T. and Coleman, A., 2020. Investigating students' attitudes, motives, participation and performance regarding out-ofclass communication (OCC) in a flipped classroom. The Electronic Journal of e-Learning, 18 (6), pp. 550-561. DOI: https://doi.org/10.34190/JEL.18.6.007.

Dagilienè, I., 2012. Translation as a learning method in English language teaching. Studies about Languages, 21, pp. 124129. DOI: https://doi.org/10.5755/j01.sal.0.21.1469.

Darling Hammond, L., Flook, L., Cook-Harvey, CH., Barron, B. and Osher, D., 2019. Implication for educational practice of the science of learning and development. Applied Development Science, 24 (2), pp. 97-140. DOI: http://doi.org/10.1080/10888691.2018.1537791.

Deli Girik Allo, M., 2020. Is the online learning good in the midst of COVID-19 pandemic? The case of EFL learners. Jurnal Sinestesia, 10 (1), pp. 1-10.

Ellis, R., Skehan, P., Li, S. and Lambert, C., 2019. Task-based language teaching: theory and practice. Cambridge: Cambridge University Press.

Fredrickson, B. L., 2001. The role of positive emotions in positive psychology: the broaden-and-build theory of positive emotions. American Psychologist, 56 (3), pp. 218-226.

Gallardo-López, J. A., 2018. Educating in emotional competences in the information and communication society. In: M. Reyes-Tejedor, et. al. (eds). Values Education in the Digital Age: An Action Training and Research Approach. Cupey: Eurytion. pp. 1-10.

Ghazi-Saidi, L. and Ansaldo, A. I., 2017. Second language world learning through repetition and imitation: functional networks as a function of learning phase and language distance. Frontiers in Human Neuroscience, 11, pp. 1-13. DOI: 10.3389/fnhum.2017.00463.

Guofang, L., 2020. Principles of developing learner agency in language learning in a new Eduscape with COVID-19. Language Learning, 5, pp. 33-43.

Guslyakova, N. and Guslyakova, A., 2020. Emotional intelligence as a driving force in the study of foreign languages in higher education. ARPHA Proceedings, 3, pp. 781-792. DOI: http://doi.org/10.3897/ap.2.e0781

Halliday, M. A. K., 1975. Learning how to mean: explorations in the development of language. London: Edward Arnold.

Hanim Rahmat, N., 2018. Educational psychology: a tool for language research. People. International Journal of Social Sciences, 4 (2), pp. 655-668. DOI: https://dx.doi.org/10.20319/pijss.2018.42.655668.

Hlas, A., Neyers, K. and Molitor, S., 2019. Measuring student attention in the second language classroom. Language Teaching Research, 23 (1), 107-125. DOI: https://doi.org/10.1177/1362168817713766.

IESALC, 2020. COVID-19 and higher education: today and tomorrow. [online]. UNESCO. Available at: https://www.iesalc.unesco.org/en/wp-content/uploads/2020/05/COVID-19-EN-130520.pdf. [Accessed 01 November 2020].

Kovács, G., 2017. Culture in language teaching. A course design for teacher trainees. Acta Univ, Sapientiae, Philologica, 9 (3), pp. 73-86. DOI: 10.1515//ausp-2017-0030.

Laremenko, N. V., 2017. Enhancing English language learner's motivation through online games. Information Technologies and Learning Tools, 59 (3), pp. 126-133.

Long, M., Wood, C., Littleton, K., Passenger, T. and Sheehy, K., 2011. The psychology of education. New York: Routledge.

Maican, M. and Cocorada, E., 2021. Higher education and its correlates during the COVID-19 pandemic. Sustainability, 13, pp.781-802. DOI: https://doi.org/10.3390/su13020781.

Maslow, A. H., 1962. El hombre autorrealizado: hacia una psicología del ser. Barcelona: Kairós.

Octavio, M. M., 2021. Design thinking: un enfoque educativo en el aula de segundas lenguas en la era pos-COVID. Tecnología, Ciencia y Educación, 18, pp. 45-75.DOI: https://doi.org/10.51302/tce.2021.569.

Ollero Ramírez, N., 2014. The influence of motivation in the foreign language learning process. Fòrum de Recerca, 19, pp. 695-707. DOI: http://dx.doi.org/10.6035/ForumRecerca.2014.19.44.

Pérez-López, E., Vásquez Atochero, A., and Cambero Rivero, S., 2021. Educación a distancia en tiempo de COVID-19: análisis desde la perspectiva de los estudios universitarios. Revista Iberoamericana de Educación a Distancia, 24 (1), pp. 330-342. DOI: https://doi.org/10.5944/ried.24.1.27855.

Perveen, A., 2016. Synchronous and asynchronous e-language learning: a case study of virtual university of Pakistan. Open Praxis, 8(1), pp. 21-39. DOI: http://dx.doi.org/10.5944/openpraxis.8.1.212.

Pokhrel, S., and Chhetri, R., 2019. A literature review on Impact of COVID-19 pandemic on teaching and learning. Higher Education for the Future, 8(1), pp. 133-141. DOI: https://doi.org/10.1177/2347631120983481.

Priyo Atmojo, A. E. and Nugroho, A., 2020. EFL classes must go online! teaching activities and challenges during COVID-19 pandemic in Indonesia. Register Journal, 13 (1), pp. 49-76. DOI: https://doi.org/10.18326/rgt.v13i1.49-76. 
Rapanta, Ch., Botturi, L., Goodyear, P., Guàrdia, L. and Koole, M., 2020. Online university teaching during and after the COVID-19 crisis: refocusing teacher presence and learning activity. Postdigital Science and Education, 2, pp. 923-945. DOI: https://doi.org/10Kovacs.1007/s42438-020-00155-y.

Reimers, F. M. and Schleicher, A., 2020. A framework to guide an education response to the COVID-19 pandemic of 2020. [online]. OECD. Available at: https://globaled.gse.harvard.edu/files/geii/files/framework guide v1 002.pdf. [Accessed 05 December 2020].

Skinner, B., 1957. Verbal behaviour. New York: Appleton Century Crofts.

Teräs, M., Suoranta, J., Teräs, H., and Curcher, M., 2020. Post-COVID-19 education and education technology 'solutionism': a seller's market. Postdigital Science and Education, 2, pp. 863-878. DOI: https://doi.org/10.1007/s42438-020-00164$\underline{x}$.

Trujillo Sáez, F., Merino, C. S., and Gabarrón Pérez, A., 2019. Tecnología para la enseñanza y el aprendizaje de lenguas extranjeras: revisión de la literatura. RIED, 22(1), pp. 153-169. DOI: http://dx.doi. org/10.5944/ried.22.1.22257.

TNTP, 2020. Supporting multilingual learners (MLLs)/ English language (ELLs) during the COVID-19 shutdown. [online] Reimagine Teaching. Available at: https://tntp.org/assets/documents/ELL and ELD At-Home Learning SupportTNTP.pdf. [Accessed 01 December 2020].

Van Nguyen, s., and Habók, A., 2021. Vietnamese non-English-major students' motivation to learn English: from activity theory perspective. Heliyon, 7, pp. 1-11. DOI: 10.1016/i.heliyon.2021.e06819.

Vermes, A., 2010. Translation in foreign language teaching: a brief overview of pros and cons. Eger Journal of English Studies, 10, pp. 83-93.

Yengin, I., Karachoca, D., Karachoca, A. and Yücel, A., 2010. Roles of teachers in e-learning: how to engage students \& how to get free e-learning and the future. Procedia Social and Behavioral Sciences, 2, pp. 2775-2787. 